\title{
Effects of low temperature on electrophysiology and mechanophysiology of human induced pluripotent stem cell-derived cardiomyocytes (hiPSC-CMs)
}

\author{
Pooja P. Kanade ${ }^{1}$, Nomin-Erdene Oyunbaatar ${ }^{1}$ and Dong-Weon Lee $1,2,3^{*}$ (D)
}

\begin{abstract}
Studies related to low temperature and their effect on cardiomyocytes are essential as hypothermia — like situations have been known to induce arrhythmia or ventricular fibrillation. Till date, several studies have been carried out on animals and their electrophysiological responses have been studied in the form of action potential. However, for a complete assessment of the effect of low temperature, mechanophysiological changes along with electrophysiological changes need to be investigated, at the tissue level. In this study, the effect of culture temperature on cell growth has been studied by measuring the field potential and contractility of human induced pluripotent stem cell-derived cardiomyocytes. This study has the potential to further improve the understanding of low temperature on human cells.
\end{abstract}

Keywords: Cardiomyocytes, Hypothermia, Temperature, Electrophysiology, Mechanophysiology

\section{Introduction}

Temperature is an important factor for the proper functioning of the cardiac muscle. Low temperatures could have extreme effects on the heart, such as prolongation of the QT interval and the QRS interval [1]. Effects including ventricular fibrillation and arrhythmia could be developed in the cardiac tissue [2-4]. The QT interval is an important parameter to detect arrhythmias, and it's the understanding of its prolongation is essential. The underlying ionic mechanisms pertaining to the prolongation of the QT interval have been discussed with the measurement of action potential using patch clamp studies [5]. Patch clamp involves the electrophysiological study of a single cell and its ionic currents. The electrophysiological effects of low temperatures at the tissue level are yet

\footnotetext{
*Correspondence: mems@jnu.ac.kr

${ }^{3}$ Advanced Medical Device Research Center for Cardiovascular Disease,

Chonnam National University, Gwangju 61186, Republic of Korea

Full list of author information is available at the end of the article
}

to be studied. Electrophysiology of the cardiac tissue can be studied with the measurement of extracellular action potential, also known as field potential. Field potential can be measured by culturing cells on microelectrode array (MEA) and simultaneously measuring the field potential from the MEA. There are several commercially available MEAs available to measure the field potential of electrogenic cells such as neurons, retinal cells and cardiomyocytes [6, 7].

On the other hand, the mechanisms pertaining to calcium signaling in the cardiomyocytes at low temperature have been studied extensively till date [8-11]. Contractility studies have also been performed in this regard on animals such as rats, rabbits and hedgehogs [12]. However, it is essential to understand the response of the human heart to low temperature in the event of hypothermia. The mechanophysiological and electrophysiological effects of low temperature have not been studied still date. 
In this study, the effect of low temperature has been studied on human induced pluripotent stem cellderived cardiomyocytes (hiPSC-CMs). We have studied the electrophysiology as well as contractility of hiPSC$\mathrm{CMs}$ from the standard temperature of 37 to $28^{\circ} \mathrm{C}$. The commercially available system of Axion Biosystems was used to perform this study. Electrophysiology was studied by measuring the field potential and contractility was studied by measuring the change in impedance between the cells and the electrode.

\section{Materials and methods}

\section{Generation of hiPSC-CMs}

hiPSC-CMs (ax2508) purchased from Axol Bioscience (UK) were utilized for this study. The cryopreserved cardiomyocytes were rapidly thawed, then diluted in maintenance medium with supplements (Axol Bioscience, ax2530-500) and $10 \%$ fetal bovine serum. Before cell culture, fibronectin was coated on the Axion Biosystems well plates to improve cell adhesion. The cells were cultured on the well plates with a density of 1000 cells $/ \mathrm{mm}^{2}$. The culture medium was replaced once every 2 days.

\section{Measurement of field potential and contractility}

The electrophysiology and mechanophysiology of the cells cultured on the Axion Biosystems well plate were measured using MEA Maestro (Axion Biosystems, USA). The parameters measured and the cells cultured on the well plate are shown in Fig. 1. Electrophysiology was measured in the form of field potential, and mechanophysiology was measured in the form of contractility. Spontaneous beats were recorded in absence of electrical stimulation. The data was recorded using the data acquisition software AxIS Navigator that was connected to the MEA Maestro. Field potential duration (FPD) was measured from the negative spike up to the last peak. FPD was measured using the Cardiac Analysis Tool software of Axion Biosystems. Contractile amplitude was measured by measuring the difference between the topmost point of contractility and the bottom-most point. Beating duration was calculated as the time difference between $10 \%$ of contraction and $90 \%$ of relaxation. Sampling rate of the system was $12.5 \mathrm{kHz}$.

To understand the effect of low temperature, field potential was measured first at the standard $37{ }^{\circ} \mathrm{C}$ followed by contractility. Then the system temperature was lowered to a temperature of $34^{\circ} \mathrm{C}$. This was done by entering the desired temperature in the AxIS Navigator software and waiting for the temperature to lower to the target temperature. After reaching the target temperature, the system was observed for an additional $5 \mathrm{~min}$ to ensure that the temperature remains constant. Thereafter, field potential was again measured followed by contractility. This process was repeated until $28^{\circ} \mathrm{C}$ in steps of $3{ }^{\circ} \mathrm{C}$. After $28^{\circ} \mathrm{C}$, the temperature was increased to $37^{\circ} \mathrm{C}$ to understand the recovery of the parameters of field potential and contractility. The process flow is shown in Fig. 2.

\section{Data analysis and statistical significance}

This study was conducted in $\mathrm{n}=5$ biologically independent samples. In each sample, data from one microelectrode was selected for analysis. Data are presented as mean \pm standard error of mean (S.E.M.). All statistical analyses were performed using the software GraphPad Prism 7. Changes in contractile and electrophysiological parameters on lowering temperature were normalized for analyses. Field potential duration (FPD) and beating duration have been corrected using Fredericia's formula (corrected duration $=$ absolute duration/(interspike interval $\left.)^{1 / 3}\right)$. Statistical significance of data was determined with the help of one-way ANOVA followed by Tukey's honest significant difference test, with significant differences defined by ${ }^{*} p<0.05,{ }^{* *} \mathrm{p}<0.001$ and $\%$ * $<0.0001$. (a)

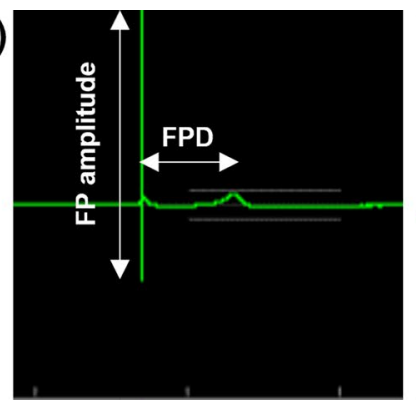

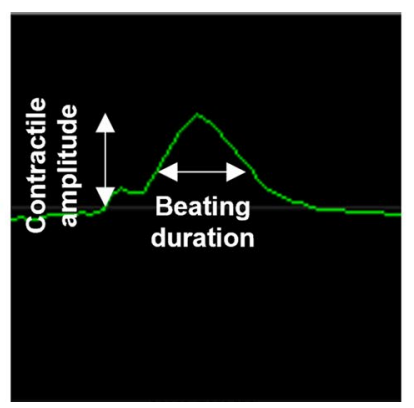

(b)

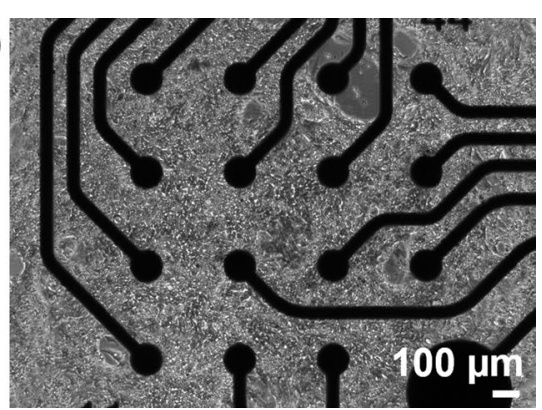

Fig. 1 a Field potential duration and field potential amplitude calculation methods from field potential graph and contractile amplitude and beating duration calculation methods from contractility graph, $\mathbf{b}$ optical image of the distribution of hiPSC-CMs cultured on the Axion biosystems well plate 

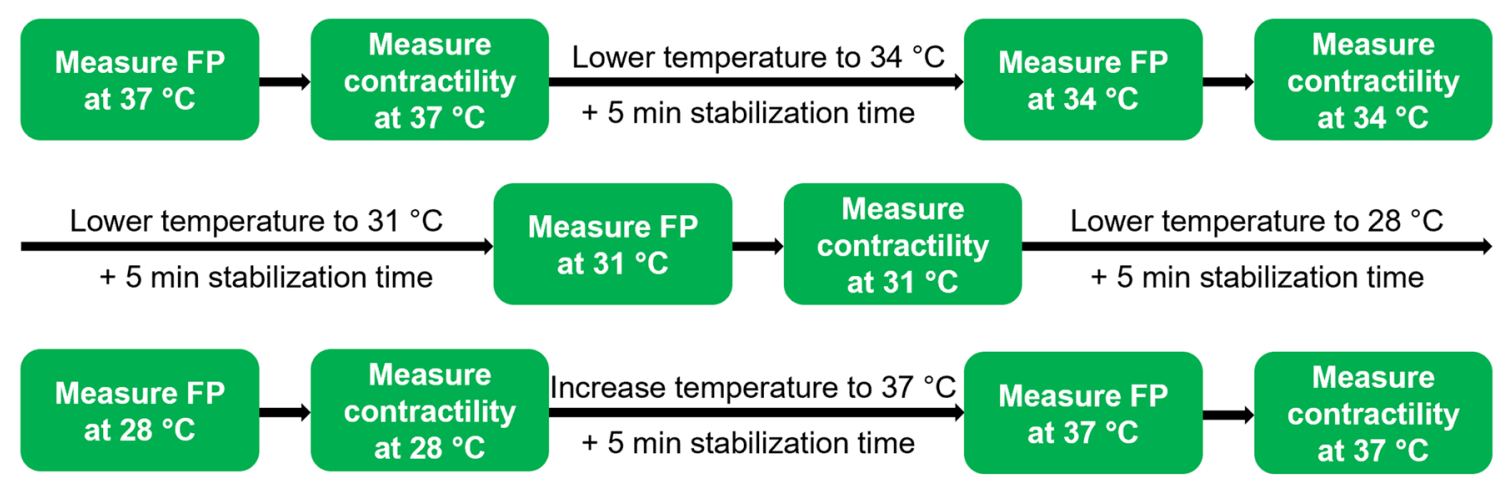

Fig. 2 Process flow followed for this study

\section{Results and discussion}

This study was carried out with the objective to understand the effect of low temperatures on cardiomyocytes. The system utilized for this purpose, i.e. Axion Biosystems, is high throughput, so that data from multiple samples could be recorded at the same time. Each well plate consists of 16 nos. of electrodes from which field potential could be measured at the same time. Contractility was measured using these electrodes by measuring the change in impedance The required temperature and $5 \%$ $\mathrm{CO}_{2}$ could be maintained as desired.

The cardiomyocytes were evenly distributed on all the electrodes, as can be seen from Fig. 1c. Cell culture density was maintained the same in all the well plates. For this experiment, the system temperature was lowered up to $28{ }^{\circ} \mathrm{C}$, and then raised back to $37^{\circ} \mathrm{C}$ to check recovery of electrophysiological and mechanophysiological parameters. Figure 3 shows the representative $10 \mathrm{~s}$ recorded data for field potential and contractility at each measured temperature from one electrode. On left side are the field potential graphs, while the contractility graphs are on the right side. It can be seen from field potential as well as contractility graphs that the interspike interval was slowly increasing with decreasing temperature. In other words, beat rate of the cells was gradually declining. Beat rate rose again at $37{ }^{\circ} \mathrm{C}$, as can be seen from Fig. 3i, j. Here, it should be noted that field potential and contractility were not measured simultaneously, but sequentially.

Figure $4 \mathrm{a}$ and $\mathrm{b}$ show the overlapped curves of field potential and contractility on decreasing the temperature. Both FPD in Fig. 4a as well as contractility in Fig. 4b increase with decreasing temperatures. The amplitude of the second peak in field potential is also decreasing. In case of contractility, the contractile amplitude is slightly decreasing but not decreasing consistently with temperature. In multiple samples, the amplitude of contractility had varied. A more detailed analysis of field potential and contractility parameters was carried which is shown in Fig. 5. The parameters analyzed in case of field potential were FPD, FPDc, $\mathrm{Na}^{+}$spike amplitude and $\mathrm{Na}^{+}$spike slope. Using contractility data, the parameters analyzed were beating duration, corrected beating duration, contractile amplitude and beating frequency.

FPD gradually increased from 1.81 times of control at $34{ }^{\circ} \mathrm{C}$ to 3.25 times at $28{ }^{\circ} \mathrm{C}$ (Fig. $5 \mathrm{a}$ ). It returned to its original value when the temperature was raised back to $37^{\circ} \mathrm{C}$. FPDc increased to 1.72 times at $28{ }^{\circ} \mathrm{C}, 2.01$ times at $31{ }^{\circ} \mathrm{C}$ and 2.34 times at $28{ }^{\circ} \mathrm{C}$. The increase in FPD and FPDc was statistically significant at all temperatures. FPDc returned around the original values $1.19 \pm 0.04$ times on raising the temperature. On the other hand, the $\mathrm{Na}^{+}$spike amplitude and slope increased slightly at $34{ }^{\circ} \mathrm{C}$ and then started decreasing. The spike amplitude was 1.20 times the original at $34{ }^{\circ} \mathrm{C}, 0.70$ times at $31{ }^{\circ} \mathrm{C}$ and 0.53 times at $28{ }^{\circ} \mathrm{C}$. Meanwhile, the spike slope at $34{ }^{\circ} \mathrm{C}$ was higher than control by 1.15 times, 0.73 times lower at $31^{\circ} \mathrm{C}$ and 0.18 times at $28^{\circ} \mathrm{C}$. When the temperature was raised back to $37{ }^{\circ} \mathrm{C}$, both these parameters could not recover fully to control values. Spike amplitude recovered 0.53 times while spike slope recovered 0.39 times that of control.

In case of the contractility measurements, the beating duration increased 1.48 times that of control at $34{ }^{\circ} \mathrm{C}$, 1.96 times at $31{ }^{\circ} \mathrm{C}$ and 2.29 times at $28{ }^{\circ} \mathrm{C}$. The change in beating duration at 31 and $28{ }^{\circ} \mathrm{C}$ was found to be statistically significant. The beating duration recovered to $0.88 \pm 0.12$ times of control on raising the temperature 
(a)

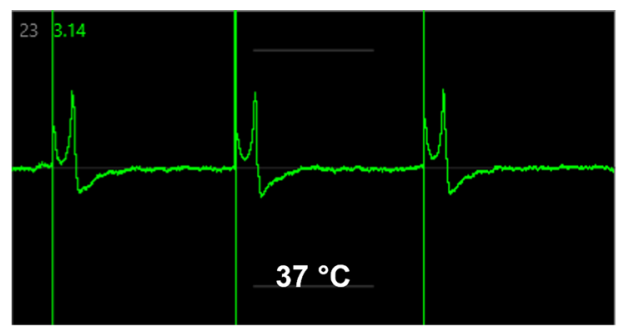

(c)

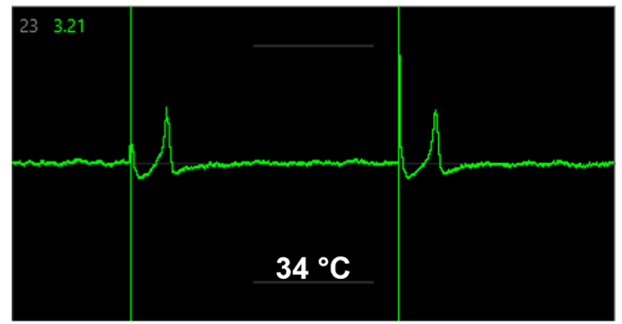

(e)

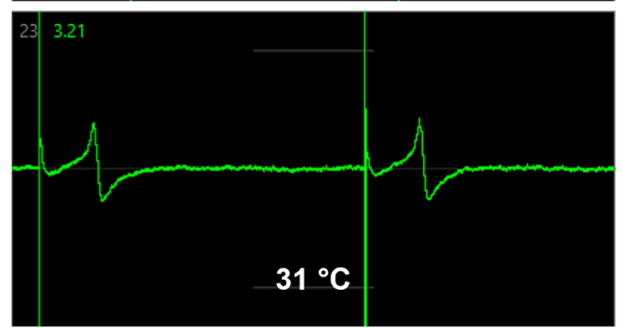

(g)

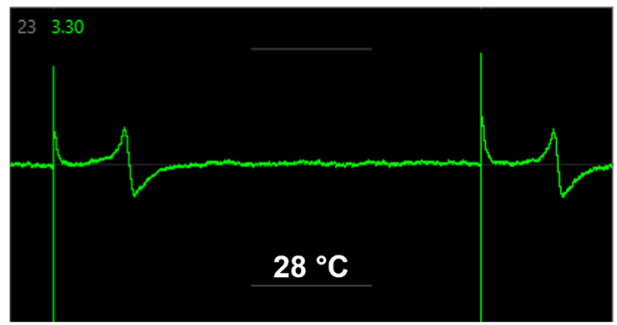

(i)

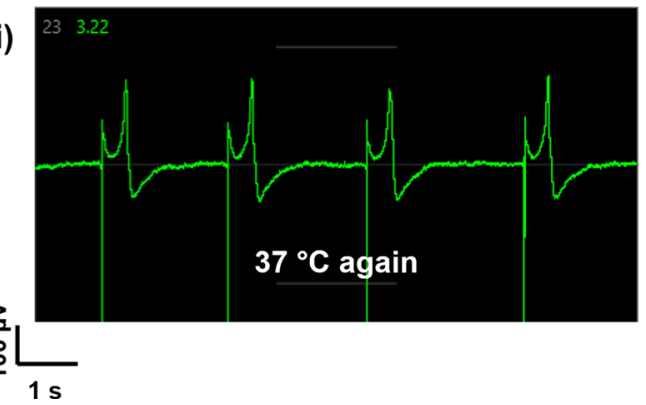

(b)

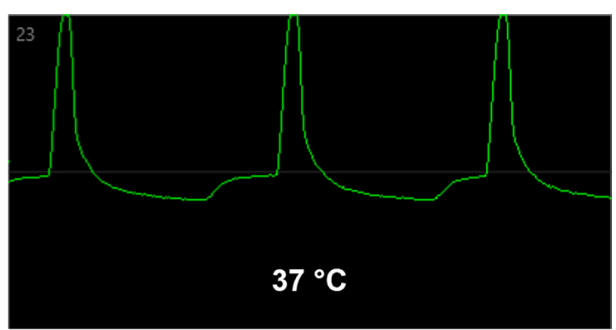

(d)

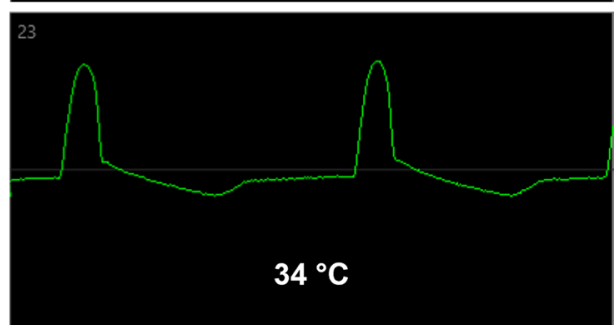

(f)

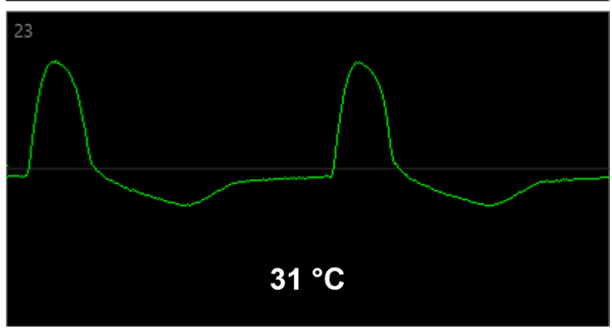

(h)

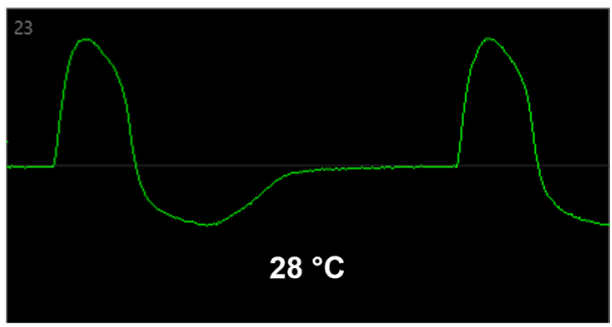

(j)

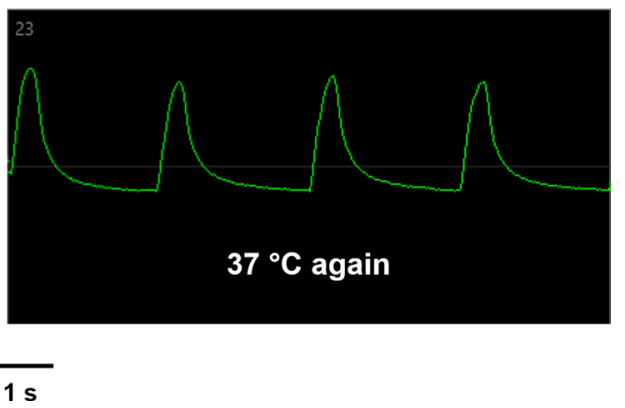

Fig. 3 Field potential (left) and contractility (right) recorded data at the system temperature of $\mathbf{a}, \mathbf{b} 37^{\circ} \mathrm{C}, \mathbf{c}, \mathbf{d} 34^{\circ} \mathrm{C}, \mathbf{e}, \mathbf{f} 31^{\circ} \mathrm{C}, \mathbf{g}, \mathbf{h} 28^{\circ} \mathrm{C}$ and $\mathbf{i}, \mathbf{j}$ raised back to $37^{\circ} \mathrm{C}$ 

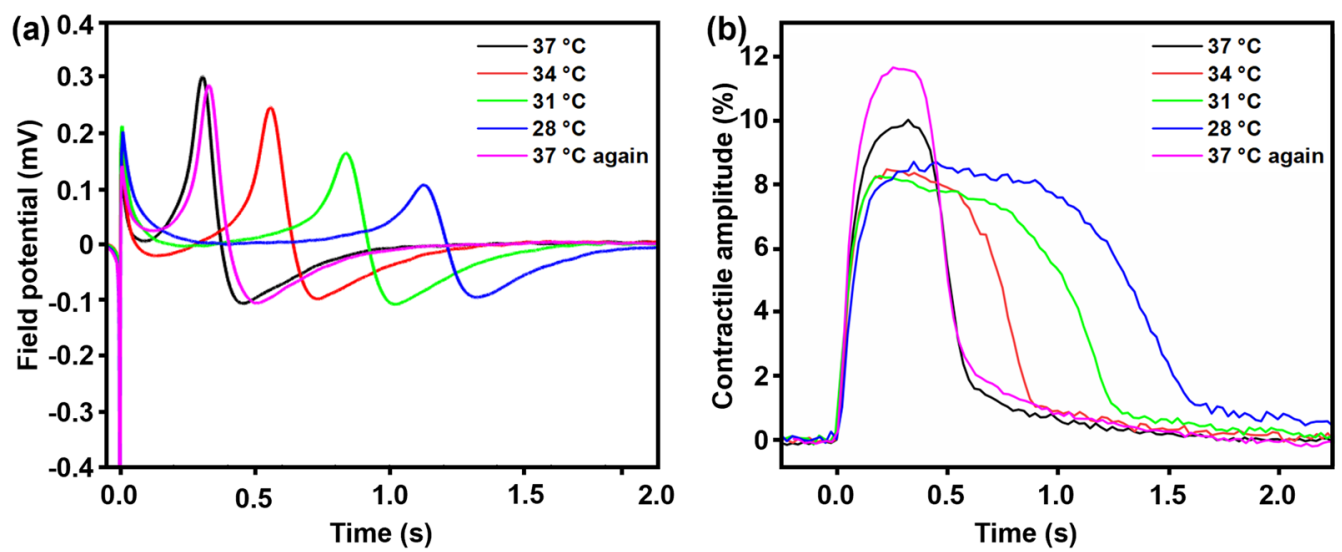

Fig. 4 a Overlapped curves of field potential at different temperatures from 37 to $28^{\circ} \mathrm{C}$, $\mathbf{b}$ overlapped curves of contractility at different temperatures from 37 to $28^{\circ} \mathrm{C}$

to $37{ }^{\circ} \mathrm{C}$. The corrected beating duration also showed increment with decreasing temperature, with 1.42 times increase at $34{ }^{\circ} \mathrm{C}, 1.84$ times at $31{ }^{\circ} \mathrm{C}$ and 2.42 times at $28{ }^{\circ} \mathrm{C}$. The corrected beating duration returned to control values on raising the temperature to $37^{\circ} \mathrm{C}$. Contrary to this, the contractile amplitude did not exhibit any specific trend with respect to temperature. In some samples, the amplitude decreased, while in some other samples, it remained the same. The beating rate, however, decreased consistently on reducing the system temperature. The spontaneous beating rate at control was $0.33 \pm 0.01 \mathrm{~Hz}$. At $34{ }^{\circ} \mathrm{C}$, it went down to $0.28 \mathrm{~Hz}, 0.27 \mathrm{~Hz}$ at $31^{\circ} \mathrm{C}$ and $0.21 \mathrm{~Hz}$ at $28^{\circ} \mathrm{C}$. When the temperature was raised back to $37^{\circ} \mathrm{C}$, the beating shot up to $0.50 \pm 0.07 \mathrm{~Hz}$, which was 1.52 times that of control.

The change in electrophysiology and mechanophysiology is a result of several changes in ionic activities occurring in the cell at lower temperatures. It has been shown that lowering of temperature leads to increase in intracellular calcium $[8,13]$. An overload of calcium can lead to cardiac dysfunction in an event of hypothermia $[8,12]$. In addition, other ionic currents like $\mathrm{I}_{\mathrm{k}}$ experience delayed activation at low temperatures [5]. The combined effect of the increased sarcoplasmic $\mathrm{Ca}^{2+}$ current and delayed $\mathrm{I}_{\mathrm{k}}$ current resulted in a delayed repolarization and, as a result, an increase in duration of the field potential
(Fig. 5a, b). The increase in $\mathrm{Ca}^{2+}$ intake and release and the delayed inactivation of the calcium ion channel contributed to the increase in beating duration (Fig. 5e, f). The spike amplitude and spike duration had decreased, that shows that the $\mathrm{Na}^{+}$current also decreased with decreasing temperature (Fig. $5 \mathrm{c}, \mathrm{d}$ ). The delay in activation of $\mathrm{Na}^{+}$channel led to the increase in interspike interval and the resultant decrease in beat rate (Fig. 5h).

\section{Conclusions}

In this study, we measured and analyzed the effect of low temperature on hiPSC-CMs tissue by measuring the field potential for electrophysiology and contractility for mechanophysiological understanding. Beat rate of the cardiac tissue decreased with decreasing temperature. In case of electrophysiological measurements, the increase in $\mathrm{Ca}^{2+}$ and delayed $\mathrm{K}^{+}$current were reflected with the prolonged FPD at reduced temperatures. Reduction in $\mathrm{Na}^{+}$current were observed with the reduction in spike amplitude and spike slope. Contractility measurements showed an increase in beating duration, as a result of increase in $\mathrm{Ca}^{2+}$ current and delayed inactivation of $\mathrm{Ca}^{2+}$ channel. This study can further help in the understanding of low temperature processes in the event of hypothermia. 

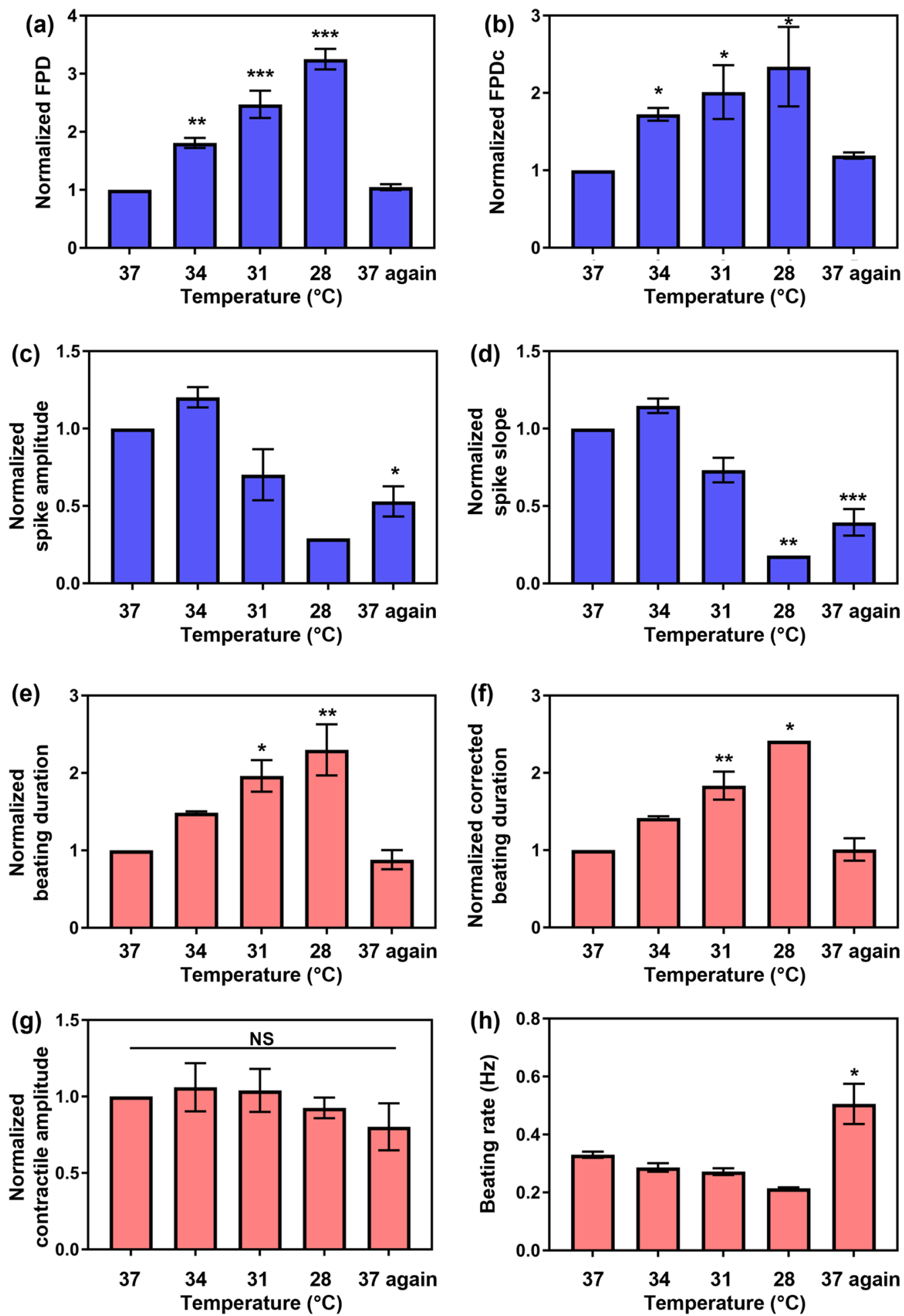

Fig. 5 Analysis of field potential and contractility parameters with respect to temperature $\left(37^{\circ} \mathrm{C}, 34^{\circ} \mathrm{C}, 31^{\circ} \mathrm{C}, 28^{\circ} \mathrm{C}\right.$ and raised back to $\left.37^{\circ} \mathrm{C}\right)$. a Normalized FPD, $\mathbf{b}$ normalized corrected FPD (FPDC), $\mathbf{c}$ normalized spike amplitude, $\mathbf{d}$ normalized spike slope, e normalized beating duration, $\mathbf{f}$ normalized corrected beating duration, $\mathbf{g}$ normalized contractile amplitude $\mathbf{h}$ beating rate. Corrected duration = measured duration/ (interspike interval) $^{(1 / 3)} \cdot n=5$ biologically independent samples. Statistical significance of data was determined with the help of one-way ANOVA followed by Tukey's honest significant difference test, with significant differences defined by ${ }^{*} p<0.05,{ }^{* *} p<0.001$ and ${ }^{* * *} p<0.0001$ 


\section{Acknowledgements}

Authors are grateful to the National Research Foundation of Korea for the funds received.

\section{Authors' contributions}

PPK proposed the concept, carried out the experiments, analyzed the experimental results, and drafted the manuscript. NEO performed the cell culture of hiPSC-CMs. DWL supervised the research and reviewed the manuscript. All the authors read and approved the final manuscript.

\section{Funding}

This study was supported by a National Research Foundation of Korea (NRF) grant funded by the Korean government (MSIT) (No. 2017R1E1A1A01074550 and No. 2020R1A5A8018367).

\section{Availability of data and materials}

The datasets supporting the conclusions of this article are included within the article.

\section{Declarations}

Ethics approval and consent to participate

Not applicable.

\section{Consent for publication}

Not applicable.

\section{Competing interests}

The authors declare that they have no competing interests.

\section{Author details}

${ }^{1}$ School of Mechanical Engineering, Chonnam National University, Gwangju 61186, Republic of Korea. ${ }^{2}$ Center for Next-Generation Sensor Research and Development, Chonnam National University, Gwangju 61186, Republic of Korea. ${ }^{3}$ Advanced Medical Device Research Center for Cardiovascular Disease, Chonnam National University, Gwangju 61186, Republic of Korea.

Received: 3 September 2021 Accepted: 22 October 2021

Published online: 28 October 2021

\section{References}

1. Kaplan JA, Wells PH (1982) Electrocardiographic monitoring. In: Ream AK, Fogdall RP (eds) Acute cardiovascular management anesthesia and intensive care. Lippincott, Toronto, pp 151-205
2. Biorck G, Johansson BW (1955) Comparative studies on temperature effects upon electrocardiogram in some vertebrates. Acta Physiol Scand 34:257-272

3. Johansson BW, BiBrck G, Haeger K, Sjiistrtim B (1956) Electrocardiographic observations on patients operated upon in hypothermia. Acta Med Scand 155:257-269

4. Steif PS, Palastro MC, Rabin Y (2007) The effect of temperature gradients on stress development during cryopreservation via vitrification. Cell Preserv Technol 5(2):104-115

5. Kiyosue T, Arita M, Muramatsu H, Spindler AJ, Noble D (1993) Ionic mechanisms of action potential prolongation at low temperature in guinea-pig ventricular myocytes. J Physiol 468(1):85-106

6. Halbach M, Egert U, Hescheler J, Banach K (2003) Estimation of action potential changes from field potential recordings in multicellular mouse cardiac myocyte cultures. Cell Physiol Biochem 13(5):271-284

7. Smith AS, Choi E, Gray K, Macadangdang J, Ahn EH, Clark EC, Laflamme MA, Wu JC, Murry CE, Tung L, Kim DH (2019) NanoMEA: a tool for highthroughput, electrophysiological phenotyping of patterned excitable cells. Nano Lett 20(3):1561-1570

8. Liu B, Wang LCH, Belke DD (1991) Effect of low temperature on the cytosolic free $\mathrm{Ca} 2+$ in rat ventricular myocytes. Cell calcium 12(1):11-18

9. Souza MMD, Boyle RT (2001) A moderate decrease in temperature inhibits the calcium signaling mechanism (s) of the regulatory volume decrease in chick embryo cardiomyocytes. Braz J Med Biol Res 34:137-141

10. Galli GL, Lipnick MS, Shiels HA, Block BA (2011) Temperature effects on $\mathrm{Ca} 2+$ cycling in scombrid cardiomyocytes: a phylogenetic comparison. J Exp Biol 214(7):1068-1076

11. Fu Y, Zhang GQ, Hao XM, Wu CH, Chai Z, Wang SQ (2005) Temperature dependence and thermodynamic properties of Ca2+ sparks in rat cardiomyocytes. Biophys J 89(4):2533-2541

12. Liu B, Wohlfart B, Johansson BW (1990) Effects of low temperature on contraction in papillary muscles from rabbit, rat, and hedgehog. Cryobiology 27(5):539-546

13. Wang S, Zhou Z, Qian H (1999) Temperature dependence of intracellular free calcium in cardiac myocytes from rat and ground squirrel measured by confocal microscopy. Sci China Ser C Life Sci 42(3):293-299

\section{Publisher's Note}

Springer Nature remains neutral with regard to jurisdictional claims in published maps and institutional affiliations.

\section{Submit your manuscript to a SpringerOpen ${ }^{\circ}$ journal and benefit from:}

- Convenient online submission

- Rigorous peer review

- Open access: articles freely available online

- High visibility within the field

- Retaining the copyright to your article

Submit your next manuscript at $\boldsymbol{\nabla}$ springeropen.com 